Statements on funding and competing interests

Funding None identifed.

Competing interests The author is a member of Abortion Rights, and by her own admission is old enough to have seen women on gynaecological wards before the Abortion Act 1967.

\section{References}

1 Argent V, Pavey L. Can nurses legally perform surgical induced abortion? J Fam Plann Reprod Health Care 2007: 33: 000-000.

2 Hadley J. Abortion: Between Freedom and Necessity. London,UK: Virago Press, 1996.

3 Government Statistical Service. Abortion Statistics, England and Wales: 2005 (Statistical Bulletin). London, UK: Department of Health, 2006. http://www.dh.gov.uk/assetRoot/04/13/ 68/59/04136859.pdf [Accessed 2 February 2007].

4 fpa. Abortion policy statement. January 2006. http://www.fpa.org.uk/attachments/published/346/Abortion.pdf [Acccessed 2 February 2007].

5 Faculty of Family Planning and Reproductive Health Care. Syllabus and Logbook for the Certificate in Abortion Care of the Faculty of Family Planning and Reproductive Health Care of the Royal College of Obstetricians and Gynaecologists. http://ffprhc.org.uk/pdfs/AbortionCareLogBook.pdf [Accessed 2 February 2007].

6 Royal College of Nursing: Nurses Working in Termination of Pregnancy Group. http://www.rcn.org.uk/specialisms [Accessed 2 February 2007].

\title{
Development of UPCASH (Update in Contraception and Sexual Health) Flexible Continuing Medical Education
}

\section{Fran Reader}

\section{Why was change needed?}

Continuing Medical Education (CME) is an essential part of clinical governance. As lead clinicians we were involved in updating staff, working in reproductive and sexual health, in our own services and primary care. We wanted a flexible CME tool that could be used for the variety of settings in which we offer updates and refreshers and which could also be used for self-directed learning.

\section{How did you go about implementing change?}

The flexible CME package was initially developed in Suffolk, UK in 1997. It was a flexible package of five modules that offered a refresher and updating of knowledge in the fields of both reproductive and sexual health. ${ }^{1}$

Since the initial work the multiple-choice questions (MCQs) have been used in a variety of ways as a CME tool. A typical approach was for an MCQ to be sent in advance to CME participants followed 1 week later by a CME discussion group, facilitated by an experienced practitioner. At the group meeting the short answers were given and a discussion followed. At the end of the meeting the longhand answers were circulated.

In 2005/2006 the UPCASH Development Team updated the reproductive health part of the package and

\section{J Fam Plann Reprod Health Care 2007; 33(2): 78}

Article written on behalf of the Update in Contraception and Sexual Health (UPCASH) Development Team

Caroline Marfleet, FFFP, Consultant in Family Planning and

Reproductive Health, Colchester General Hospital, Essex Rivers NHS Trust

Kate Nash, FFFP, Consultant in Family Planning and Reproductive Health, Norfolk and Norwich University Hospital NHS Trust Fran Reader, FFFP, Consultant in Reproductive Health, Suffolk PCT

Correspondence to: Dr Caroline Marfleet, Constable Wing, Colchester General Hospital, Turner Road, Colchester CO4 5LJ, UK. E-mail:marfleets@doctors.org.uk developed the UPCASH website (www.upcash.co.uk).

The current flexible package contains four reproductive health modules as follows:

1 Hormonal contraception

2 Non-hormonal contraception

3 Uterine contraception

4 Emergency contraception.

This package will be updated in January each year or as appropriate if essential information changes. In 2007 it is hoped to expand the package to include modules in termination of pregnancy and the menopause.

Sections can be downloaded from the website and used by trainers to pick and mix from the modules. The modules can also be used to support self-directed learning at home.

The website contains the complete CME package; the MCQs for each of the four modules, together with the short and long answers where the true and false answers are expanded and points for discussion explained. Relevant references are also provided.

\section{What advice would you give to others considering a similar course of action?} The UPCASH site is not copyright protected and so the modules can be downloaded and adapted for local training programmes. We would, however, expect both the website and the original authors to be acknowledged.

\section{How did you show that change had occurred?}

This was demonstrated by positive evaluation of training events.

\section{Acknowledgements}

The UPCASH Development Team would like to acknowledge the support provided by Organon for the development of the original MCQs in 1997 and Schering for the development of the updated MCQs and website in 2005/2006.

\section{Reference}

1 Reader F, Hunt K, Passmore H, Royce S, Adapa U. Professional development in reproductive and sexual health a pilot study from Suffolk, UK. Br J Fam Plann 1999; 24: 135-140. 